Témoigner Témoigner. Entre histoire et mémoire

Getuigen Revue pluridisciplinaire de la Fondation Auschwitz

$126 \mid 2018$

Questions sur l'avenir du travail de mémoire

\title{
De Rechtvaardigen onder de naties in een pedagogische context
}

Het geval Zwitserland

Les justes parmi les Nations dans un contexte pédagogique : quelques réflexions

à partir du cas suisse

\section{François Wisard}

Traducteur : Rita Roggen

\section{(2) OpenEdition}

\section{Journals}

Édition électronique

URL : https://journals.openedition.org/temoigner/7192

DOI : 10.4000/temoigner.7192

ISSN : 2506-6390

Cet article est une traduction de :

Les justes parmi les Nations dans un contexte pédagogique : quelques réflexions à partir

du cas suisse - URL : https://journals.openedition.org/temoigner/7160 [fr]

Éditeur :

Éditions du Centre d'études et de documentation Mémoire d'Auschwitz, Éditions Kimé

Édition imprimée

Date de publication : 2 avril 2018

Pagination : 54-61

ISBN : 978-2-930953-06-9

ISSN : 2037-4183

Référence électronique

François Wisard, «De Rechtvaardigen onder de naties in een pedagogische context», Témoigner. Entre histoire et mémoire [Online], 126 | 2018, Online op 20 janvier 2022, geraadpleegd op 04 février 2022. URL: http://journals.openedition.org/temoigner/7192 ; DOI: https://doi.org/10.4000/temoigner.7192 


\section{De Rechtvaardigen onder de naties in een pedagogische context \\ Het geval Zwitserland}

$\rightarrow$ François Wisard
Vertaling uit het Frans: Vertaling uit he
Rita Roggen

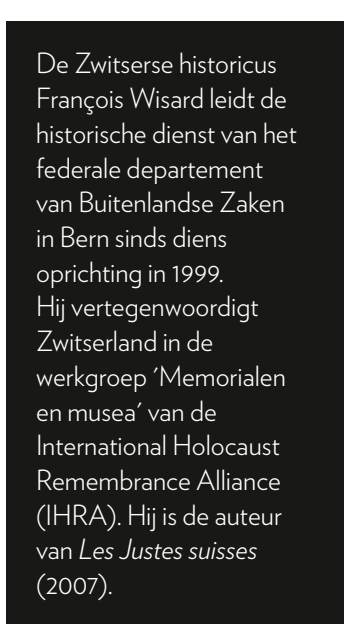

\section{INLEIDING}

M t deze bijdrage wil ik enkele algemene overwegingen en thema's voorstellen met betrekking tot de Rechtvaardigen onder de naties, uitgaande van het concrete voorbeeld Zwitserland. De Rechtvaardigen onder de naties zijn mensen die niet van Joodse origine zijn en sinds 1962 door het instituut Yad Vashem in Jerusalem worden geëerd. De onderscheiding kan eventueel postuum worden toegekend en eert mannen en vrouwen die Joden hebben gered tijdens de Shoah, zonder geldgewin en met gevaar voor hun eigen leven of hun vrijheid.

De Rechtvaardigen, en meer algemeen de redding van de Joden, vormen vandaag de dag zonder de minste twijfel een belangrijk thema in de herinnering aan de Shoah (zie meer bepaald Gensburger 2015, 537-555). Voor het ogenblik bedraagt het aantal Rechtvaardigen meer dan 26000 . Dat aantal is de laatste decennia sterk gestegen. Ongeveer twee derde van alle onderscheidingen die gedurende iets meer dan vijftigjaar werden verleend, dateren uit de laatste vijfentwintig jaar. Bovendien bevatten tentoonstellingen over de geschiedenis van de Shoah tegenwoordig bijna altijd een luik over de inspanningen die werden geleverd om Joden te redden. Tot slot moeten we wijzen op de werken of projecten vanwege ministeries van But teries van Butentom voor het voetlicht te brengen, zoals in Portugal en in Spanje in 2000 (Baer \& Corre Martin-Aroyo 2015, Franco \& Fevereiro 2000), en de tali ike activiteiten die in Zweden en Hongarije werden georganiseerd voor Raoul Wallenberg in 2012, het jaar van zijn honderdste verjaardag. Het risico bestaat er natuurlijk in dat dit soort activiteiten een actuele politieke agenda dient.

Welke rol hebben de Rechtvaardigen in Zwitserland gespeeld, en spelen ze nog vandaag, in het herinneringswerk? Het begrip 'Zwitserse Rechtvaardige' roept een reeks vragen op, net als overigens dat van 'Franse' of 'Poolse Rechtvaardige', om maar twee andere voorbeelden te noemen. Maar laten we voor het ogenblik enkel verduidelijken dat Yad Vashem zowat zeventig personen heft on tijdens de Sho de Zwitserse nation tijdens de Shoah de Zwitserse nationaliteit hadden. Sinds de jaren tachtig van de
vorige eeuw hebben verscheidene daarvan getuigenissen gepubliceerd of waren ze het voorwerp van een boek of een documentaire. ${ }^{1}$ Toch vinden we geen enkele hit voor 'Rechtvaardigen' in de zowat 40000 artikelen van het woordenboek Historisches Lexikon der Schweiz, een collectief project dat destijds werd opgezet. ${ }^{2}$ Aan het eind van de vorige eeuw had het lot van de Rechtvaardigen dat toen bekend raakte, nog geen plaats gevonden binnen het collectieve geheugen. Twee fenomenen getuigen van een wijziging in de situatie: het blijvende belang voor de twee meest symbolische figuren van de 'Zwitserse Rechtvaardigen' en het verschijnen van specifiek pedagogisch materiaal.

Carl Lutz (1895-1975), een Zwitsers diplomaat in Boedapest, en Paul Grüninger (1891-1972), commandant van de politie van het grenskanton Sankt-Gallen ten tijde van de Anschluss van Oostenrijk, zijn beslist de twee figuren onder de 'Zwitserse Rechtvaardigen' die buiten het nationale kader treden. Het zijn voorbeeldfiguren, zoals we later zullen zien, maar niet bepaald representatief. Ook al was hun lot al goed gekend en gedocumenteerd, toch waren Lutz en Grüninger pas onlangs het voorwerp van nieuwe films en boeken. De film Akte Grüninger ${ }^{3}$ uit 2013 werd zestien jaar na een eerste documentaire gerealiseerd, die op haar beurt was gebaseerd op een werk dat aan de oorsprong lag van het eerherstel van Grüninger gedurende de eerste helft van de jaren negentig van de vorige eeuw (Grüniger's fall, 1997; vgl. Keller 1993)

Voor Lutz is de recente belangstelling nog opvallender, zonder daarom een wetenschappelijke vernieuwing te betekenen. Na een eerste boek in 1988 (Grossman 1988) volgden het referentiewerk van Theo Tschuy in 1995, vertaald in verschillende talen, dan een eerste film tien jaar later (Pasotti \& Sofia 2004). Dat stond recent echter een opmerkelijke ontwikkeling niet in de weg: twee nieuwe boeken, een derde in voorbereiding, en een reizende tentoonstelling van de Stichting Lutz in Boedapest die in 2008 werd geopend in de zetel van de Verenigde Naties in New York en sindsdien in een tiental of zelfs twintigtal steden te gast was. ${ }^{4}$ Aan die lijst moet een tweede film worden toegevoegd, die werd uitgebracht in 2014. Hij heeft de kenmerkende titel Carl Lutz dervergessene Held en de Z Witserse regisseur heeft toegegeven dat hij deze 'vergeten held' nog maar net had ontdekt.

Ook bij het pedagogische materiaal merken we een hernieuwde belangstelling voor de 'Zwitserse Rechtvaardigen'. In 2003 publiceerden de edities van de Pedagogoor de 'Zwitserse Rechtvaardigen'. In 2003 publiceerden de edities van de Pedagogische Hogeschool van Zürich een werk over de Duitse redders en Rechtvaardigen. basis van interviews uit de jaren zestig (Kosmala \& Ludewig-Kedmi 2003). Drie jaar later verzocht een Joodse organisatie met vestiging in Romaans Zwitserland ondergetekende om een tweede werk met een pedagogisch doel te wijden aan de Zwitserse Rechtvaardigen, na een brochure over het voormalige vernietigingskamp van Auschwitz-Birkenau (Wisard 2007). Tot slot heeft het kanton Luzern in Centraal-Zwitserland, datbijzonder actiefblijft in het organiseren van de internationale

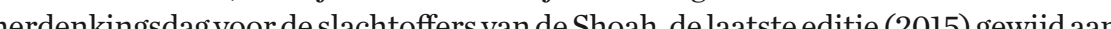
herdenkings o deShoah, maar evengoed na 1945. Vijf Rechtvaardigen met de Zwitserse nationaliteit

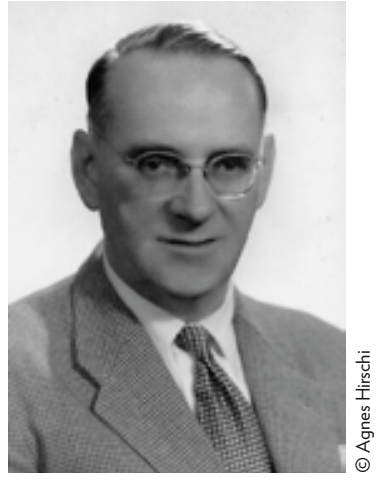

_ Carl Lutz, medewerker bij het Zwitserse gezantschap in Hongarije in 1944-1945 Erkend als Rechtvaardige
onder de Naties in 1964. 1985; Veuve 1987; Grossmant 1988. Ben-Tov 1988; Steiger 1992: Tschuy 1995; Pasche 1995. (2) www.hls-dhs-dss.ch, geraadpleegd 29 januari 2018. (3) Meer info op www.
grueninger-film.com. Opmerking: een van de protagonis
personage.

(4) Boeken: Vámos 2012: \& Schallie (red.) (in druk). The Legendary Glars Lutzand Budapest, www.uveghaz.org. In tegenstelling tot Grüninger werd Lutz nooit ontslagen uit zijn
functie of veroordeeld functie of veroord
(vgl. Jorio 2016). (5) Persdossier voor Carl Lutz,
der vergessene Held. Ein Kino-
Defer Dokumentarth von Daniel vo Aarburg, http:///Wwww.urania-n
hu/docs/saito/MediendossierCLnnir-140618_neu.pdf p. 10. 
De Rechtvaardigen onder de naties in een pedagogis het geval Zwitserland
(vervolg) onderdak had verleend in zijn naburige boerderij en een identiteitsbewijs wilde overhandigen, wat het kind geweigerd heeft, werd dan weer niet onderscheiden (Wisard 2007, 29). ${ }^{6}$ Dit voorbeeld - en er zullen er nog wel meer zijn - toont aan dat de leerling beslissende elementen over het hoofd kan zien als de aandacht zich beperkt tot de Rechtvaardigen onder de naties. Dat risico betreft evengoed de interpretatie van de reddingsacties als de evaluatie van de verdiensten van elkeen. De leerling zal deze evaluatie beslist uitvoeren.

De verruiming metandere reddingsacties dan dievan de Rechtvaardigen is zonder meer belangrijk in het onderwijs. Deze aanpak mag er echter niet toe leiden dat alle reddingsacties even hoog worden ingeschat. De figuur van de Rechtvaardige omvat in elk geval drie veelbelovende elementen binnen een pedagogische context: de Rechtvaardigen hebben immers risico's genomen, ze hebben gehandeld zonder blijk te geven van enig eigenbelang, en ze hebben hulp geboden aan de andere - aan een persoon met een andere geloofsovertuiging dan zijzelf. Eenvoudig samengevat kan men zeggen dat het daden van altruïstische moed zijn, die totaal niet evident of spontaan zijn. Ze verschillen daardoor bijvoorbeeld van de daden van bepaalde passeurs, die zeker ook levens hebben gered, maar hun slachtoffers hebben beroofd, of ook van de vaders en moeders die hun leven op het spel hebben gezet om een kind te redden.

Er doen zich twee denkbeeldige situaties voor: de (toekomstige) redder kent de person den, of hij kent deze niet. Deze beide situaties komen voor bij de Rechtward metZwite die de kinderente die de kinderen van de Joodse familie voor wie ze werkte, onder haar hoede heeft genomen of de pastoor uit de Cévennes die beslist om de onbekende jonge Jood die 's nachts aan zijn deur klopt, binnen te laten. De daad van altruistische moed waarvoor de Rechtvaardige symbool staat, is belangrijk binnen een pedagogische context, omdat hij de leerlingen aanzet om na te denken over de keuzemogelijkheden, de bewegingsruimte die je hebt in tragische situaties - en die waarschijnlijk groter is dan je op het eerste gezicht zou denken.

\section{IS DE NOTIE 'ZWITSERSE' OF 'FRANSE RECHTVAARDIGE'} helemer voorzitterschap van een overlevende. Maar ze ontbreekt Held Afor Held. Afhankelijk van het feit of leerlingen de tentoonstelling of de film zien, zullen ze een duidelijk verschillende visie hebben.

Anderzijds werden een aantal niet-Joden die hulp hebben geboden aan Joden om de een of andere reden niet onderscheiden met de titel van Rechtvaardige. Hun daden kunnen even lovenswaardig blijken. Zo werd een Zwitser die deelnam aan hulpacties in het zuiden van Frankrijk onderscheiden met de titel van Rechtvaardige voor het afgeven van zijn paspoort aan een Joods kind dat ging proberen over de Zwitserse grens te geraken, ook al heeft datkind uiteindelijk probern het identiteis

\section{EVIDENT EN PERTINENT?}

De eerste vraag leek vanzelfsprekend, over de beperkingen van een benaderingswijze die enkel rekening zou houden met de Rechtvaardigen. De tweede vraag lijkt zonder meer verbazingwekkend, zelfs onwelvoeglijk. Zoals men weet, publiceert Yad Vashem statistieken per land over de Rechtvaardigen die werden onderscheiden. Hoe moet je echter omgaan met de dubbele nationaliteit, of landen waarvan de grenzen zijn gewijzigd tussen het moment van de reddingsactie en de beslissing van Yad Vashem?

In verband met Zwitserland is er een ander probleem. De meerderheid van de Rechtvaardigen met de Zwitserse nationaliteit werd onderscheiden voor acties in Frankrijk. Zij staan meestal op de lijst 'Zwitserland' van Yad Vashem. Maar twintig
(6) De meeste hierna geciteerde
voorbeelden komen uit het werk van Wisard 
De Rechtvaardigen onder de naties in een pedagogis het geval Zwitserland
(vervolg) anderen staan op de lijst 'Frankrijk'. ${ }^{7}$ Puur anekdotisch moeten we vermelden dat de eerste naam op de lijst 'Zwitserland' die van een persoon is die verscheidene nationaliteiten heeft gehad, maar nooit de Zwitserse, het land waar hij vast en zeker geboren werd, maar dat hij op de leeftijd van twee jaar definitief verliet.

In die context heeft het erg weinig zin om een volledige en coherente lijst op te stellen van de 'Zwitserse Rechtvaardigen'. Het is verstandiger en wetenschappelijk pertinenter om meer dan één lijst op te maken: de Rechtvaardigen met de Zwitserse nationaliteit op het ogenblik van de redding zij die de dubbele nationaliteit bezit( ten op het ogenblik van de beslissing van Yad Vashem, de vreemdelingen die Zwit sers werden door huwelijk en de Zwitserse vrouwen die hun nationaliteit hebben verloren door huwelijk, en tot slot de Rechtvaardigen met een heel indirecte banc met Zwitserland, zoals de eerste naam op de lijst 'Zwitserland' van Yad Vashem. Het zou vanzelfsprekend bijzonder ongeloofwaardig zijn als men de namen op de lijsten eenvoudigweg zou samentellen. Deze overweging toont het belang aan van een transnationale benadering en de noodzaak om de historische context te reconstrueren waarbinnen de acties hebben plaatsgevonden. De risico's verbonden aan de redding van Joden waren beduidend groter in Polen (doodstraf) dan in Zwitserland, bijvoorbeeld, of zelfs in Frankrijk (voor de kwestie van de verschillen tussen de risico's, vgl, Cabanel 2012 97-102).

Leerlingen laten reflecteren over daden van moed en altruïsme, zoals die van de Rechtvaardigen - maar net zo goed van andere personen - vereist ook dat de aandacht wordt gevestigd op de verschillen tussen alle individuele acties. Dat brengt ons bij de laatste kwestie: die van het exemplarische karakter en de representativiteit van de Rechtvaardigen.

BESTAAN ER VOORBEELDFIGUREN

VAN RECHTVAARDIGEN ONDER DE NATIES?

Het antwoord is vanzelfsprekend 'ja'. Er bestaan 'voorbeeldfiguren'. Denken we gewoon maar aan Raoul Wallenberg, Oskar Schindler of ook aan Aristides de Sous Mendes, of, voor Zwitserland, aan Carl Lutz en aan Paul Grüninger. ${ }^{8}$ Welke acties hebben de beide Zwitsers ondernomen? (vgl. Keller 1993; Tschuy 1995)

Carl Lutz heeft bij het Zwitserse gezantschap' in Boedapest gewerkt van 1942 tot aan het eind van de oorlog. Hij leidde er de afdeling van de buitenlandse belangen en beheerde in die hoedanigheid de vertegenwoordiging van de Britse en Amerikaanse belangen en die van een dozijn andere staten bij de Hongaarse regering en, na maart 1944, ook bij de Duitse bezetter. Het Britse mandaat stond centraal bij de redding van de Joden, aangezien het de Joodse emigratie inhield van Hongarije naar Palestina. Op basis van dat mandaat en vertrekkende van een wettelijke emigratie tot in maart 1944, heeft Carl Lutz met de hulp van andere personen een diplomatiek beschermingsystem brieven pasteem. In
Lutz een brief geschreven om hem te bedanken, omdat de organisatie het mogelijk heeft gemaakt 62000 Joden uit Boedapest te redden. ${ }^{10}$ Paul Grüninger heeft van zijn kant de politie van het belangrijkste grenskanton met Oostenrijk voor en na de Anschluss geleid. Hij wordt gewaardeerd voor het feit dat hij duizenden Joden heeft geholpen om uit Oostenrijk te vluchten. Hij heeft daarvoor zelfs documenten vervalst, waardoor hij niet enkel werd ontslagen uit zijn functies, maar zelfs strafrechtelijk werd veroordeeld.

Voorbeeldfiguren, zonder de minste twijfel. Maar representatief zijn ze zeker niet. Lutz en Grüninger waren ambtenaren die actief waren in Zwitserland en in Hongarije. Bij de zowat zeventig Rechtvaardigen met de Zwitserse nationaliteit gedurende de Shoah was de overgrote meerderheid actief in Frankrijk en de helft van hen was bovendien een vrouw. Verder waren er beduidend meer mensen uit de Kerk bij dan functionarissen. Als men de focus op de grote figuren legt, trekt men dus het geheel scheef.

Een tweede probleem houdt verband met het quasi systematische gebruik van de term 'held', bijvoorbeeld in de titel van de laatste film over Lutz. De Rechtvaardigen hebben onweerlegbaar blijk gegeven van grote moed. Toch zien enkelen van hen zich in geen geval als helden en ze staan er evenmin op zo genoemd te worden. Hoe kun je niet ontroerd zijn door de getuigenis van de dochter van een Zwitserse dominee die door Yad Vashem werd onderscheiden:

Ik ben een deel van de namen en de feiten vergeten die mijn vader citeerde, en hij deed het ook hoogst zelden. Hij wilde dat mijn man en ik alles zouden verbranden wat hij na de oorlog, enkele uren voor zijn dood, heeft opgeschreven.

Kortom, een groot aantal Rechtvaardigen beschouwde deze daden als iets 'normaals', het was vanzelfsprekend. Als we ons binnen een pedagogische context concentreren op de grote figuren, op de 'helden', op 'buitengewone' acties, lopen we het risico dat de leerlingen menen dat ditideal gewoon onbereikbaar blijft, dat gelijkaardige acties, die ze zelf zouden kunnen ondernem in de toekomst, gemediatiseerd zouden moeten worden om publiek te worden erkend als 'heldendaad'.

Zich concentreren op de grote figuren van de Rechtvaardigen houdt nog een ander gevaar in. De historische context, zelfs de collectieve dimensie van bepaalde acties, wordt terzijde geschoven. Carl Lutz heeft bijvoorbeeld gehandeld met de hulp van jonge zionisten (dat zagen we al), maar ook van medewerkers van het Zwitserse gezantschap. Drie van hen, waarvan er een door de Sovjets werd gevangengenomen, net als Raoul Wallenberg, werden onderscheiden met de titel van Rechtvaardige. Ze komen echter niet voor in de film Carl Lutz, der vergessene Held. De organisatie die me vroeg om een boek over de Zwitserse Rechtvaardigen te schrijven, wilde die oorspronkelijk de opdracht maar aangenomen op voorwaarde dat ik het geheel thematisch mocht

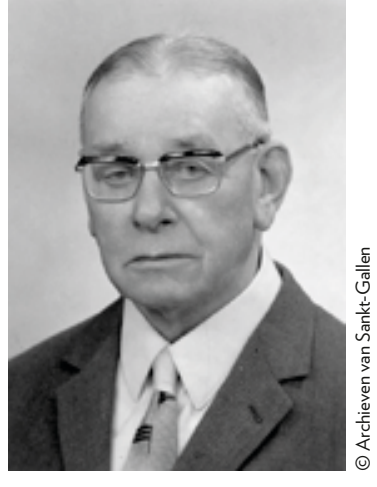

- Paul Grüninger, van het grenskanton SanktGallen ten tijde van de Enschluss van Oostenrijk onder de Naties in 1971 . 
De Rechtvaardigen onder de het geval Zwitserland haties in een pedagogisc

historische context, een historiografische balans opmaken en de belangrijkste bronnen aangeven

Het thema van de Rechtvaardigen binnen een pedagogische context benaderen kan niet zonder te reflecteren over de bronnen. De hedendaagse geschreven sporen zijn zeldzaam, vaak zelfs onbestaande, gezien de aard zelf van deze illegale en gevaarlijke activiteiten. De dossiers van Yad Vashem bevatten over het algemeen de achteraf opgestelde getuigenissen van geredde personen en ze geven vooral uitle over het moment vand de reding waarbij de historischecontext of $z$ elf hetlevenvan over het oposten van de Rechtvaardige of de geredde persoon in de schaduw worden gesteld. In sommige
gevallen beschikken we over meer documentatie.

Laten we nog een laatste punt in verband met de kwestie van de voorbeeldfunctie onderzoeken. We hebben vastgesteld dat het niet volstaat zich te beperken tot de grote figuren. Voorts past Yad Vashem geen enkel verschil toe bij de toekenning van titels. Of er slechts een enkele persoon werd gered dan wel verschillende duizenden personen door een enkele Rechtvaardige maakt geen enkel verschil uit. De titel blijft dezelfde, de medaille eveneens. Die bevat de volgende boodschap: 'Wie een leven redt, redt de hele wereld.' Het is dus de daad van de redding die wordt onderscheiden. Het aantal geredde personen speelt geen rol.

Een dergelijke benadering is absoluut heilzaam, omdat het noodzakelijk is om - Joden verdringen zich Departement emigratie van het Zwitserse gezantschap
in Boedapest. 列 Het geheel van de Rechtvaardigen op hetzelfde niveau plaatsen is echter niet zonder enig gevaar. Enerzijds is er het gevaar verbonden aan het onderscheid tussen de Rechtvaardige en de personen die niet werden geëerd, niettegenstaande minstens even waardevolle acties. Anderzijds is er het gevaar dat men de proporties uit het oog zou kunnen verliezen of de cijfers in hun totaliteit. Honderden Joden redden in een bezet land in Oost-Europa is toch niethetzelfde als een Joodse familie in Zwitserland op te nemen Geschiedschrijving vergt altijd contexten serland op te ner proporties. Hethering context, wint er zeker bij als we daar rekening mee houden
FILMOGRAFIE

- Richard Dindo, Grüninger's Fall, film, SRF, 1997, 100 min. Alain Gsponer, Akte Grüniger, film, SRF, 2013, 96 min., www grueninger-film.com

Enrico Pasotti \& Aldo Sofia, La casa di vetro. Storia di Carl Lutz, lo svizzero che salvo 62000 ebrei, film, TSI, $2004,87 \mathrm{~min}$

- Jacqueline Veuve, La filière, documentaire, TVCO, 1987, 37 min. Daniel von Aar
2014,90 min.

\section{TENTOONSTELLINGEN}

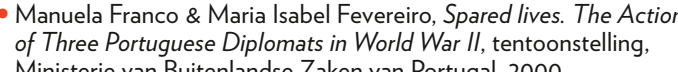

Stichting Lutz Carl Lutz and the Legendary Glass House in Budapest Stichting Lutz, Carl Lutz and the Legend
tentoonstelling, www.uveghaz.org.
BIBLIOGRAFIE

- Alejandro Baer \& Pedro Correa Martin-Arroyo, 'The Politics of Spain. From Francoist Humanitarianism to Rescuers or Perpetrators? The Neutral Countries and the Shooh, Berlij. Metropol, 2015, 205-216. - Arieh Ben-Tov, Facing the Holocaust in Budapest. The International
Committee of the Red Cross and the Jews in Hungary 1943-1945,

Friedel Bohny-Reiter, Journal de Rivesaltes 1941-1942, uitgegeven door
Michèle Fleury-Seemüller, Genève: Zoé, 1993.

Patrick Cabanel, Histoire des Justes de France. Parijs: Armand Colin

- Sarah Gensburger, "La diffusion internationale de la catégorie de "Juste de 'homme et globalisation de la mémoire', Revue internationale de politique comparée 22(4), 2015, 537-555. Aktion. Geschichte und Porträt, Waldgut Wald, 1988.

- Agnes Hirschi \& Charlotte Schallie (red.), Under Swiss Protection.
Jewish Eye-witness Accounts from Wartime Budapest, Stuttgart, in druk - Anne-Marie Im Hof-Piguet, La Filière - en France occupée 1942-1944, Yverdon-les-Bains: la Thiele, 1985

- Marco Jorio, Judenretter Carl Lutz', NZZ Geschichte 7, 2016, 120-12. - Stefan Keller, Grüningers Fall: Geschichten von Flucht und Hilfe, Zurich:

- Beate Kosmala \& Revital Ludewig-Kedmi, Verbotene Hilfe. Deutsche 2003 .

- Marcel Pasche, Années de guerre et de fraternité, Le Mont-sur-
Lausanne: Ouverture, 1995. - Erika Rosenberg, Carl Lutz und die Rettung ungarischer Juden vor dem
Holoccaust, München: Herbig, 2016.

- Sebastian Steiger, Die Kinder von Schloss La Hille, Bazel: BrunnenVerlag, 1992.

- Theo Tschuy, Carl Lutz und die Juden von Budapest, Zürich: NZZ

- György Vámos, Carl Lutz (1895-1975). Diplomate suisse à Budapest en
1944. Un Uuste parmi les Nations, Gollion: Infolio, 2012. - François Wisard, Les Justes suisses. Des actes de courage méconnus au
temps de la Shoah, Genève: CICAD, 2007. 